\title{
Publicidade e propaganda em websites de cirurgiões-dentistas nas regiões brasileiras: aspectos éticos e legais
}

Advertising and propaganda on dentistry surgery websites in brazilian regions: ethical and legal aspects

\section{Publicidad y propaganda en sitios web de dentistas en regiones brasileñas: aspectos éticos y legales.}

Edja de Cássia Pereira Costa ${ }^{1}$, Rodrigo da Costa Silva ${ }^{1}$, Ingrid Ferreira Leite ${ }^{1 *}$, Mayssa Galvão Pimentel ${ }^{1}$, Marcílio Otávio Brandão Peixoto¹, João Francisco Tenório Neto¹.

\section{RESUMO}

Objetivo: Este trabalho teve como objetivo analisar websites de Cirurgiões-dentistas e confrontar o seu conteúdo com as diretrizes deontológicas e legais que regulamentam a publicidade e propaganda da Odontologia no país, a fim de averiguar possíveis irregularidades cometidas por estes profissionais nas regiões brasileiras. Métodos: Este trabalho trata-se de um estudo observacional transversal, onde a obtenção dos dados foi feita através de um formulário constituído por 25 itens de avaliação ética/jurídica, aplicado em uma amostra de 244 websites de Cirurgiões-dentistas, registrados sob o domínio "odo.br". Resultados: Os 244 websites estão distribuídos da seguinte forma: 5 websites são da região Norte, 15 da região Nordeste, 56 da região Sul, 144 da região sudeste e 24 da região Centro-Oeste. Conclusão: A maioria dos websites analisados apresentam irregularidades em seu conteúdo, principalmente na região Nordeste onde foram observados índices mais elevados de itens em desacordo com as normas que regulamentam a publicidade e propaganda da Odontologia no país.

Palavras-Chave: Ética Odontológica, Internet, Publicidade como assunto.

\begin{abstract}
Objective: The purpose of this study was to analyze the Dental Surgeons websites and compare their content with the legal and de ontologic guidelines that regulate the advertising and propaganda of dentistry in the country, in order to investigate possible irregularities committed by these professionals in the Brazilian regions. Methods: This work is a cross-sectional observational study, where the data were obtained through a form consisting of 25 ethics and legal evaluation items, applied in a sample of 244 Dental Surgeons websites, registered under domain "odo.br". Results: The 244 websites are distributed as follows: 5 websites are from the North, 15 from the Northeast, 56 from the South, 144 from the Southeast and 24 from the Midwest Regions of the country. Conclusion: Most of the analyzed websites had irregularities in their content, especially in the Northeast region, where highest rates were observed items in disagreement to the norms that regulate the publicity and propaganda of dentistry in the country.
\end{abstract}

Key words: Dentistry ethics, Internet, Advertising as a subject.

\section{RESUMEN}

Objetivo: Este trabajo tuve como objetivo analizar sitios web de cirujanos-dentistas y confrontar su contenido, con las directrices odontológicas y legales que reglamentan la publicidad y propaganda de la Odontología en el país, a fin de averiguar posibles irregularidades cometidas por estos profesionales en las regiones brasileñas. Métodos: Este trabajo se trata de un estudio observacional transversal, donde la obtención de los datos fue hecha a través de un formulario constituido por 25 elementos de evaluación ética/jurídica aplicado en una amuestra de 244 sitios web de cirujanos-dentistas registrados bajo el dominio "odo.br". Resultados:

${ }^{1}$ Centro Universitário Cesmac, Maceió-Alagoas. *E-mail: ingrid-leite@hotmail.com 
Los 244 sitios web están distribuidos de la siguiente forma: 5 sitios web son de la Región Norte, 15 de la Región Nordeste, 56 de la Región Sul, 144 de la Región Sudeste y 24 de la Región Centro-Oeste. Conclusión: La mayoría de los sitios web analizados presentan irregularidades en su contenido, principalmente en la Región Nordeste donde fueron observados índices más elevados de elementos en desacuerdo con las normas que reglamentan la publicidad y propaganda de la Odontología en el país.

Palabras clave: Ética Odontología, Internet, Publicidad como asunto.

\section{INTRODUÇÃO}

O Brasil está em primeiro lugar entre os países com o maior número de Cirurgiões-dentistas do mundo. Este número é crescente e distribuição no país é desigual, gerando uma maior concorrência, principalmente nas regiões onde há uma concentração maior destes profissionais, por isso, muitos se preocupam em qualificar-se e adquirir outros títulos acadêmicos, assim, a publicidade e a propaganda torna-se uma ferramenta fundamental para enfrentar um mercado de trabalho cada vez mais competitivo. (MELO AUC, et al., 2012; MIRANDA SS, et al., 2015; LIMA AIC, et al., 2016).

Apesar de a publicidade, a propaganda e o marketing se assemelharem devido à característica em comum da persuasão, estes, possuem conceitos diferentes. A publicidade é o ato de divulgar um produto ou serviço com fins comerciais; já a propaganda tem o intuito de propagar ideias e teorias sem, necessariamente, fins comerciais; e, o marketing é um processo que envolve estratégias e ações que tem a finalidade de atrair, manter e satisfazer as necessidades de indivíduos (GONÇALEZ MC, 2009; MIRANDA SS, et al., 2015).

No meio odontológico, a publicidade e propaganda é uma alternativa que os cirurgiões-dentistas encontram para atrair e fidelizar seus pacientes, onde o sucesso de uma clínica pode ser determinado, em grande parte, através do marketing que é de indiscutível importância e quando bem executado, pode estabelecer, entre profissionais e pacientes, uma relação contínua, oferecendo soluções capazes de atender as carências e expectativas de ambos. Uma clínica com os olhos voltados para o marketing pode criar uma proposta de valor de um serviço que satisfaça integralmente às necessidades dos seus pacientes (PARANHOS LR, et al., 2010).

A publicidade odontológica pode ser feita por meio de um website, que é uma página na web que permite aos usuários realizar, de forma fácil e segura, as ações de sua vontade e pode ser usada pelos Cirurgiõesdentistas para expandir o acesso direto à informação e atrair novos pacientes (MIRANDA GE, et al., 2013).

Os websites de Cirurgiões-dentistas, assim como qualquer outro veículo de comunicação que se utilize de publicidade e propaganda odontológica, devem seguir as regulações deontológicas e legais. A divulgação de informações enganosas ou abusivas nesses websites constitui infração ética e devem ser evitadas, tanto para que não haja sanções contra o profissional, quanto para não promover a desvalorização da profissão (MIRANDA GE, et al., 2013).

O Código de Ética Odontológica (CEO), aprovado pela resolução CFO-118/2012, regula os direitos e deveres do Cirurgião-dentista e dos profissionais que exercem atividades na área da Odontologia, em âmbito público e/ou privado. Seu texto deixa claro que o objetivo de toda a atenção odontológica é a saúde do ser humano e caberá aos profissionais da Odontologia, dirigir ações que visem satisfazer as necessidades de saúde da população (CFO, 2012).

Outro Código que deve ser observado pelo Cirurgião-dentista em suas atividades de prestação de serviços é o Código de Defesa do Consumidor (CDC), que é a lei $n^{\circ} 8.078$, de 11 de setembro de 1990, onde a obrigatoriedade da informação, veracidade, disponibilidade e transparência são princípios, os quais devem ser aplicados à publicidade de acordo com esse Código (BRASIL, 1990; PARANHOS LR, et al., 2010).

O Conselho Nacional de Auto-Regulamentação Publicitária (CONAR) é uma instituição que foi criada com objetivo principal de regulamentar a publicidade e propaganda no país, defendendo os interesses do consumidor ou de empresas e promovendo a liberdade de expressão publicitária (CONAR, 1980). 
Há, também, a Lei que regulamenta o exercício da Odontologia no Brasil que é a Lei federal 5.081 de 24 de agosto de 1966. Segundo o artigo $7^{\circ}$ dessa Lei é vedado ao Cirurgião-dentista o exercício de mais de duas especializações, bem como, "anunciar preços de serviços, modalidades de pagamento e outras formas de comercialização da clínica que signifiquem competição desleal" (BRASIL, 1966).

Diante da depreciação das diretrizes deontológicas e legais por parte de muitos Cirurgiões-dentistas, associado a uma comunicação odontológica muitas vezes mercantilista oriunda de um mercado cada vez mais saturado, os dados levantados por esta pesquisa podem ajudar aos Conselhos Regionais de Odontologia a observar melhor como a publicidade e propaganda estão sendo realizadas em Websites e pode também, servir como parâmetro e orientar as faculdades de Odontologia a terem uma atenção especial na formação acadêmica dos futuros Cirurgiões-dentistas, no tocante aos preceitos éticos e legais da profissão.

Este trabalho teve como objetivo analisar websites de Cirurgiões-dentistas e confrontar o seu conteúdo com as diretrizes deontológicas e legais que regulamentam a publicidade e propaganda da Odontologia no país, a fim de averiguar possíveis irregularidades cometidas por estes profissionais nas regiões brasileiras.

\section{MÉTODOS}

Trata-se de um estudo observacional transversal, onde a obtenção dos dados foi feita através de um formulário constituído por 25 perguntas que foi elaborado por Miranda GE, et al. (2013), aplicado em websites de Cirurgiões-dentistas encontrados na rede mundial de computadores, portanto, de acesso público e irrestrito.

A amostra foi composta por 244 websites, obtidos através de um processo de saturação das buscas, momento em que nenhuma outra nova página pode ser encontrada. Foram avaliados websites registrados sob o domínio <odo.br>, domínio este, destinado à categoria de Cirurgiões-dentistas (profissionais liberais), obtido através do "Registro.br" que é o departamento do Núcleo de Informação e Coordenação do Ponto BR (NIC.br) responsável pelas atividades de registro e manutenção dos nomes de domínios que usam o "br".

Foi utilizado um computador pessoal com acesso à internet banda larga e com auxílio do mecanismo de busca $G_{0 o g l e} \Omega$, foi realizada a pesquisa utilizando "odo.br" como palavra-chave. A pesquisa foi realizada entre os dias 20/11/2016 a 20/12/2016. Em um único dia foram salvas as páginas com todos os websites com domínio <odo.br> que surgiram na pesquisa realizada através do buscador Google ${ }^{\circledR}$, a fim de evitar a atualização de novos websites. Posteriormente, esses websites foram abertos um a um e foram analisados com o auxílio do instrumento de coleta de dados desta pesquisa. Os websites que estavam em manutenção, construção ou indisponíveis foram excluídos.

As informações obtidas nos websites estavam disponíveis ao público, porém, não existem elementos nesta pesquisa que possam identificar o website e o profissional. Os dados serão exibidos através de estatística descritiva para resumir, compreender e descrever os dados obtidos.

\section{RESULTADOS E DISCUSSÃO}

Existem, no Brasil cerca de 284.945 Cirurgiões-dentistas. Segundo Morita MC, et al. (2010), o Brasil tem cerca de $20 \%$ dos Cirurgiões-dentistas de todo o mundo, tornando-o o país com o maior número destes profissionais. Além disso, 58\% da população brasileira são usuários de internet o que representa 102 milhões de internautas. Desta forma, é fácil considerar que os profissionais utilizem cada vez mais a internet como um veículo para a utilização de estratégia de marketing, na tentativa de atrair mais pacientes, o que torna 0 mercado de trabalho altamente competitivo (NIC.BR, 2016; CFO, 2017).

O estado de São Paulo é o estado brasileiro com o maior número de Cirurgiões-dentistas com 86.736, seguido por Minas Gerais com 33.844 e Rio de Janeiro com 30.545 mostrando que a região Sudeste possui o maior número de profissionais do país (CFO, 2017).

No presente estudo foram encontrados 244 websites de Cirurgiões-dentistas com domínio "odo.br". Enquanto na região Norte foram encontrados 5 websites, no Nordeste 15, no Sul 56 e no Centro-Oeste 24, 
na região sudeste foram encontrados 144 websites, que correspondem a $59 \%$ de todos os websites analisados, sugerindo que quanto maior o número de profissionais em determinada região, mais esta ferramenta de marketing será utilizada. A busca destes websites proporcionou frequências absoluta e relativa das variáveis analisadas (Tabela 1).

Tabela 1 - Frequências absoluta e relativa das variáveis analisadas.

\begin{tabular}{|c|c|c|c|c|}
\hline VARIÁVEL ANALISADA & & Sim & & Não \\
\hline & $\mathrm{N}$ & $\%$ & $\mathrm{~N}$ & $\%$ \\
\hline O website possui o nome do profissional? & 225 & 92,21 & 19 & 7,78 \\
\hline $\begin{array}{l}\text { O website possui o número de inscrição no Conselho } \\
\text { Reqional de Odontologia do profissional? }\end{array}$ & 123 & 50,40 & 121 & 49,59 \\
\hline $\begin{array}{l}\text { O website possui o nome representativo da profissão de } \\
\text { Ciruraião-dentista? }\end{array}$ & 88 & 36,06 & 156 & 63,93 \\
\hline $\begin{array}{l}\text { O website possui áreas de atuação, procedimentos e técnicas } \\
\text { de tratamento? }\end{array}$ & 225 & 92,21 & 19 & 7,79 \\
\hline $\begin{array}{l}\text { O website informa se o profissional é especialista? } \\
0 \text { website possui a expressão "clínico-geral" pelos }\end{array}$ & $\begin{array}{c}169 \\
33\end{array}$ & $\begin{array}{l}69,26 \\
13,52\end{array}$ & $\begin{array}{l}75 \\
211\end{array}$ & $\begin{array}{l}30,73 \\
86,47\end{array}$ \\
\hline $\begin{array}{l}\text { Odontologia decorrentes de conhecimentos adquiridos em } \\
\text { curso de graduação ou em cursos de pós-graduação? }\end{array}$ & & & & \\
\hline $\begin{array}{l}\text { O website anuncia o exercício de mais de duas } \\
\text { especialidades para um mesmo profissional? } \\
\text { O website possui informaçóes sobre títulos de formação }\end{array}$ & 19 & 7,78 & 225 & 92,21 \\
\hline $\begin{array}{l}\text { Acadêmica stricto sensu e do magistério relativos à } \\
\text { profissão? }\end{array}$ & 99 & 40,57 & 145 & 59,42 \\
\hline O website informa o endereço do consultório? & 240 & 98,36 & 4 & 1,63 \\
\hline O website informa o número do telefone ou fax para contato? & 241 & 98,77 & 3 & 1,22 \\
\hline la o horário de trabalho? & 62 & 25,40 & 182 & 74,59 \\
\hline ha sobre convênios ou credenciamentos? & 40 & 16,39 & 204 & 83,60 \\
\hline $\begin{array}{l}\text { O website faz propaganda de atendimento domiciliar e } \\
\text { hospitalar? }\end{array}$ & 14 & 5,73 & 230 & 94,26 \\
\hline O website possui logomarca ou logotipo? & 210 & 86,06 & 34 & 13,93 \\
\hline $\begin{array}{l}\text { O website anuncia preço, serviços gratuitos, modalidades de } \\
\text { pagamento ou outras formas que impliquem comercialização } \\
\text { da Odontoloqia? }\end{array}$ & 19 & 7,78 & 225 & 92,21 \\
\hline $\begin{array}{l}\text { O website utiliza expressões e/ou imagens do tipo "antes, } \\
\text { durante e depois" relativas a procedimentos odontológicos? }\end{array}$ & 88 & 36,06 & 156 & 63,93 \\
\hline $\begin{array}{l}\text { O website anuncia procedimentos usando a toxina } \\
\text { botulínica? }\end{array}$ & 20 & 8,19 & 224 & 91,80 \\
\hline Há testemunhos de pacientes? & 29 & 11,88 & 215 & 88,11 \\
\hline O website traz informações relativas à saúde bucal? & 90 & 36,88 & 154 & 63,11 \\
\hline O website traz a data da última atualização? & 2 & 0,81 & 242 & 99,18 \\
\hline O website traz o endereço eletrônico para contato? & 168 & 68,85 & 76 & 31,14 \\
\hline $\begin{array}{l}\text { O website traz sistema eletrônico para marcação de } \\
\text { consultas? }\end{array}$ & 64 & 26,22 & 180 & 73,77 \\
\hline Há seção de perguntas/respostas frequentes? & 37 & 15,16 & 207 & 84,83 \\
\hline $\begin{array}{l}\text { Há cadastro de e-mail para recebimento de mala-direta } \\
\text { eletrônica ou newsletter? }\end{array}$ & 17 & 6,96 & 227 & 93,03 \\
\hline O website traz um link para o CRO ou CFO? & 15 & 6,14 & 229 & 93,85 \\
\hline
\end{tabular}

Fonte: Dados da pesquisa, 2019.

Segundo o CEO, em seu artigo 43, "Na comunicação e divulgação é obrigatório constar o nome e o número de inscrição da pessoa física ou jurídica, bem como o nome representativo da profissão de Cirurgiãodentista..." (CFO, 2012, p. 14). Também o CONAR em seu anexo "L", diz que:

"os anúncios de profissionais liberais, com profissão definida e regulamentada em lei, terão que conter o nome do Anunciante, seu título profissional, [...] e o número de seu registro na respectiva Ordem ou Conselho" (CONAR, 1980, p. 25). 
A divulgação do nome do profissional é importante, pois auxilia o paciente na identificação do Cirurgiãodentista. Martins ALG, et al. (2011) revelaram que $64 \%$ dos anúncios não continham o nome do Cirurgiãodentista, contrastando com a presente pesquisa, onde foi observado que apenas $7,78 \%$ dos websites analisados não traziam o nome do profissional, mostrando uma diminuição no índice de irregularidade referente a este item.

Todavia, aproximadamente a metade dos websites analisados $(49,59 \%)$ não trazia o número de inscrição no CRO, já em um estudo realizado por Garbin AJl, et al. (2010), esse índice foi de 34,8\%. A divulgação do número de inscrição no $\mathrm{CRO}$ é de grande relevância, pois age como referência para certificar o exercício legal e regular do profissional.

Dos 244 websites analisados o item obrigatório mais ausente foi o nome representativo da profissão de Cirurgião-dentista com 63,93\%, no estudo de Garbin AJI, et al. (2010), observou-se que 34,3\% dos anúncios não traziam o nome representativo da profissão. Um índice mais elevado foi encontrado por Martins et al. (2011), onde 94,7\% dos anúncios não constavam tal item. A ausência dessa informação pode causar incerteza ao paciente quanto ao título do profissional e os serviços prestados por este.

O trabalho de Garbin AJl, et al. (2010), mostrou que 44,9\% dos anúncios traziam todos os itens obrigatórios, diferentemente do estudo de Martins et al. (2011), que apresentou um índice de apenas $2 \%$. Outro estudo apresentou um índice de $16 \%$ (SASSI C, et al., 2013) e a presente pesquisa 20,08\%. Tais índices demostram que, ainda existe uma grande parcela de profissionais que não seguem as normas de obrigatoriedade de dados referentes à publicidade e propaganda que regem a profissão. Para Garbin AJl, et al. (2010), há uma crescente publicidade odontológica antiética e com isso uma desvalorização profissional.

No presente estudo, a região Sul foi a região que apresentou os maiores percentuais de inclusão na maioria dos itens obrigatórios nos websites analisados, enquanto que a região Nordeste apresentou os menores índices, isso sugere que grande parte dos profissionais do nordeste, provavelmente, desconhecem as diretrizes deontológicas e legais que regulamentam a publicidade e propaganda da Odontologia no país (Tabela 2).

Tabela 2 - Distribuição regional do percentual dos websites que anunciam os itens obrigatórios de acordo com o Código de Ética Odontológica.

\begin{tabular}{lllllll}
\hline & \multicolumn{2}{l}{ NORTE NORDESTE } & SUL & SUDESTE & C.OESTE & GERAL \\
\hline NOME DO & $100 \%$ & $80 \%$ & $96,42 \%$ & $92,36 \%$ & $87,50 \%$ & $92,21 \%$ \\
PROFISSIONAL & & & & & & \\
No DO CRO & $40 \%$ & $33,33 \%$ & $67,85 \%$ & $43,75 \%$ & $62,50 \%$ & $50,40 \%$ \\
NOME & $40 \%$ & $33,33 \%$ & $41,07 \%$ & $34,02 \%$ & $37,50 \%$ & $36,06 \%$ \\
REPRESENTATIVO DA PROFISSÃO & & & & & & \\
TODOS OS ITENS & $20 \%$ & $13,33 \%$ & $32,14 \%$ & $15,27 \%$ & $25 \%$ & $20,08 \%$ \\
\hline
\end{tabular}

Fonte: Dados da pesquisa, 2019.

De acordo com o CEO, no parágrafo $1^{\circ}$, inciso I, os profissionais poderão ainda anunciar:

"áreas de atuação, procedimentos e técnicas de tratamento, desde que precedidos do título da especialidade registrada no Conselho Regional ou qualificação profissional de clínico geral. Áreas de atuação são procedimentos pertinentes às especialidades reconhecidas pelo Conselho Federal" (CFO, 2012, p. 14).

Enquanto que no Código de Defesa do Consumidor, no artigo 37, parágrafo 1ํㅜㄹ informa que:

"é enganosa qualquer modalidade de informação ou comunicação de caráter publicitário, inteira ou parcialmente falsa, ou, por qualquer outro modo, mesmo por omissão, capaz de induzir em erro o consumidor a respeito da natureza, características, qualidade, quantidade, propriedades, origem, preço e quaisquer outros dados sobre produtos e serviços" (BRASIL, 1990, p. 10). 
Mediante o exposto, a presente pesquisa revelou que 92,21\% dos websites apresentavam anúncios de área de atuação, procedimentos e técnicas de tratamento, destes, $23,55 \%$ não informavam se são especialistas ou clínicos gerais que atuam na área. Sassi C, et al. (2013), descrevem em seu estudo que 36\% dos anúncios traziam tal especificação e $30 \%$ deles, não incluíam a expressão "clínico geral" ou "especialista". Os profissionais anunciam áreas de atuação como ferramenta de marketing, para mostrar a diversidade de procedimentos que são realizados na clínica, com o intuito de atrair potenciais pacientes.

Contudo, o profissional que anuncia área de atuação sem ser especialista, como por exemplo, anunciar ortodontia ao invés de ortodontista, pode confundir o paciente, que é considerado como leigo e pode interpretar o anúncio de forma diferente, ficando sem saber se está na presença de um especialista ou clínico geral. Dessa forma, o paciente pode utilizar o CDC e o CEO como base para uma eventual denúncia contra o Cirurgião-dentista (MARTINS ALG, et al., 2011). Se o profissional quiser anunciar determinada área de atuação, sem ser especialista, deve tomar cuidado na hora do anúncio e deixar claro que é clínico geral, além disso, os anúncios de titulação acadêmica, endereço comercial, telefone, e-mail, convênios, horário de atendimento, logomarca e logotipo são permitidos pelo CEO (CFO, 2012).

Dentre estes itens, destacaram-se como mais divulgados, endereço da clínica $(98,36 \%)$ e telefone ou fax $(98,77 \%)$. Neste trabalho observou-se que $5,73 \%$ dos websites anunciam atendimento domiciliar e hospitalar, um pouco diferente do estudo de Miranda GE, et al. (2013), onde apenas 1,89\% dos profissionais anunciam esse tipo de atendimento, mostrando que ainda existem poucos profissionais que atuam fazendo esse tipo de assistência, mas vem se percebendo um considerável incremento nestas áreas mais novas (Tabela 3).

Tabela 3 - Distribuição regional dos percentuais dos websites que anunciam os itens permitidos de acordo com o Código de Ética Odontológica.

\begin{tabular}{lcclllc}
\hline & NORTE & NORDESTE & SUL & SUDESTE & C. OESTE & GERAL \\
\hline TÍTULO ACADÉMICO & $40 \%$ & $33,33 \%$ & $42,85 \%$ & $40,97 \%$ & $37,5 \%$ & $40,57 \%$ \\
$\begin{array}{l}\text { (STRICTO SENSU) } \\
\text { ENDEREÇO }\end{array}$ & $100 \%$ & $100 \%$ & $100 \%$ & $97,22 \%$ & $100 \%$ & $98,36 \%$ \\
TELEFONE & $100 \%$ & $100 \%$ & $100 \%$ & $97,91 \%$ & $100 \%$ & $98,77 \%$ \\
EMAIL & $80 \%$ & $53,33 \%$ & $73,21 \%$ & $67,36 \%$ & $75 \%$ & $68,85 \%$ \\
HORÁRIO DE & $60 \%$ & $40 \%$ & $32,14 \%$ & $21,52 \%$ & $16,66 \%$ & $25,40 \%$ \\
$\begin{array}{l}\text { TRABALHO } \\
\text { CONVÊNIOS }\end{array}$ & $20 \%$ & $40 \%$ & $10,71 \%$ & $13,19 \%$ & $33,33 \%$ & $16,39 \%$ \\
$\begin{array}{l}\text { AT.DOMICILIAR/ } \\
\text { HOSPITALAR }\end{array}$ & $20 \%$ & $13,33 \%$ & $1,78 \%$ & $6,94 \%$ & 0 & $5,73 \%$ \\
$\begin{array}{l}\text { LOGOMARCA E/OU } \\
\text { LOGOTIPO }\end{array}$ & $80 \%$ & $93,33 \%$ & $87,5 \%$ & $85,41 \%$ & $83,33 \%$ & $86,06 \%$ \\
\hline
\end{tabular}

Fonte: Dados da pesquisa, 2019.

Nos demais itens permitidos, os resultados mostraram que $86,06 \%$ dos websites trazem logomarca e/ou logotipo, 68,85\% apresentaram endereço eletrônico para contato, 40,57\% informam títulos de formação acadêmica stricto sensu e do magistério relativos à profissão, $25,40 \%$ anunciam o horário de atendimento e $16,39 \%$ convênios e credenciamentos. Percentuais inferiores para estas variáveis foram observados no estudo de Serra MC, et al. (2005). Estes itens podem auxiliar o Cirurgião-dentista como ferramentas de marketing, tanto para dar mais credibilidade do ponto de vista do marketing pessoal, quanto facilitando 0 acesso do paciente ao consultório.

Quanto às infrações éticas, segundo a Lei federal 5.081 de 24 de agosto de 1966, que regulamenta o exercício da Odontologia no Brasil, no artigo $7^{\circ}$, alínea "c", é vedado ao Cirurgião-dentista, o exercício de mais de duas especialidades. A mesma regra pode ser observada no CONAR em seu anexo "G". Mas, esse impedimento se refere à inscrição e ao anúncio de mais de duas especialidades e não exatamente ao seu exercício (BRASIL, 1966; CONAR, 1980; LIMA ALC, et al., 2016).

Ainda na Lei 5.081/66 em seu artigo $7^{\circ}$, alínea "g", expressa a proibição de "anunciar preços de serviços, modalidades de pagamento e outras formas de comercialização da clínica que signifiquem competição desleal" (BRASIL, 1966). 
O artigo 44, inciso I do CEO, descreve que constitui infração ética:

"fazer publicidade e propaganda enganosa, abusiva, inclusive com expressões ou imagens de antes e depois, com preços, serviços gratuitos, modalidades de pagamento, ou outras formas que impliquem comercialização da Odontologia..." (BRASIL, 2012, p. 15).

No inciso XII do mesmo artigo reforça-se que é considerado infração ética, de propaganda enganosa, anunciar imagens e/ou expressões de "antes, durante e depois", relativas a procedimentos odontológicos, assim como exposto no artigo 37, parágrafo $1^{\circ}$ do CDC. Os dados referentes às infrações éticas desta pesquisa estão dispostos na Tabela 4.

Tabela 4 - Distribuição regional dos percentuais dos websites que anunciam os itens considerados infrações éticas de acordo com as normas regulamentadoras.

\begin{tabular}{ccccccc}
\hline & NORTE & NORDESTE & SUL & SUDESTE & C.OESTE & GERAL \\
\hline MAIS DE DUAS & & & & & & \\
ESPECIALIDADES & $20 \%$ & 0 & $10,71 \%$ & $8,33 \%$ & $8,33 \%$ & $7,78 \%$ \\
$\begin{array}{c}\text { MODALIDADES } \\
\text { DE PAGAMENTO }\end{array}$ & 0 & $20 \%$ & $8,92 \%$ & $6,94 \%$ & $4,16 \%$ & $7,78 \%$ \\
ANTES E DEPOIS & $40 \%$ & $40 \%$ & $33,92 \%$ & $38,19 \%$ & $25 \%$ & $36,06 \%$ \\
\hline
\end{tabular}

Fonte: Dados da pesquisa, 2019.

Não é proibido ao profissional se qualificar e obter mais de duas especializações, no entanto, só é permitido ao Cirurgião-dentista a inscrição e anúncio de no máximo duas especialidades. No estudo de Lima ALC, et al. (2016) realizado em redes sociais, não foi observado nenhum perfil com essa irregularidade. Por outro lado, este trabalho mostrou que $7,78 \%$ dos websites trazem esse tipo de propaganda, diferentemente do que mostra o trabalho de Miranda GE, et al. (2013), que apresentou 2,86\%, evidenciando um aumento dessa irregularidade na publicidade em websites, isso ocorre, talvez, devido à concorrência acirrada fazendo com que, atualmente, exista uma procura maior do Cirurgião-dentista em especializar-se, na tentativa de ampliar as suas áreas de atuação.

Este trabalho revelou que $7,78 \%$ dos websites analisados anunciam preços, serviços gratuitos ou modalidades de pagamento e $36,06 \%$ trazem imagens de antes e depois. Comparando esses dados com os dados de Miranda GE, et al. (2013), nota-se a similaridade às infrações de modalidades de pagamento, preços e serviços gratuitos (5,99\%), já para as infrações de imagens tipo antes e depois $(53,12 \%)$, nota-se que houve uma redução no número de websites que fazem uso desse tipo de propaganda, mas que ainda existe um número elevado de publicidades em desacordo com os preceitos éticos vigentes.

O uso de imagens do tipo antes e depois tanto é considerado infração ética perante o CEO, como representa propaganda enganosa perante o CDC (CFO, 2012). A crescente busca pelos procedimentos com finalidade terapêutica, funcional e estética (lentes de contato, toxina botulínica, preenchimento) somados a possibilidade de usar fotografias de antes e depois, induz o paciente a falsa impressão de que este obterá os mesmos resultados mostrados nas imagens divulgadas (MELO AUC, et al., 2012).

O uso da toxina botulínica era permitido ao Cirurgião-dentista apenas para uso terapêutico e proibido para fins exclusivamente estéticos, permitido para procedimentos odontológicos e vedado para fins não odontológicos, segundo as resoluções CFO-112/2011, 145/2014, 146/2014. Revogando essas resoluções, entra em vigor a resolução $n^{\circ} 176$, de 06 de setembro de 2016, que em seu artigo $1^{\circ}$ resolve: "Autorizar a utilização da toxina botulínica e dos preenchedores faciais pelo Cirurgião-dentista, para fins terapêuticos funcionais e/ou estéticos, desde que não extrapole sua área anatômica de atuação" (CFO, 2016, p. 2).

O próprio artigo define que a área anatômica de atuação do Cirurgião-dentista é superiormente ao osso hioide, até o limite do ponto násio e anteriormente ao tragus, abrangendo estruturas anexas e afins (CFO, 2016). 
Apenas $8,19 \%$ dos websites anunciam o uso da toxina botulínica. Apesar de haver poucos profissionais que anunciam esse procedimento, esse número vem crescendo, quando comparado ao estudo realizado por Miranda GE, et al. (2013), onde não foi observado nenhum anúncio desse tipo. Esse crescente número, provavelmente se dá, pelo fato do pouco tempo da legalização de seu uso em procedimentos estéticos. Salienta-se ainda que, não foi observado nenhum website com esse tipo de propaganda na região Nordeste, já na região Norte esse percentual foi de $20 \%$.

Não existe impedimento, perante o CEO, para a utilização de testemunho de pacientes pelos Cirurgiõesdentistas. Já no CONAR, em seu anexo "G", consta em um de seus princípios, que na propaganda de tratamentos clínicos e cirúrgicos não devem conter o depoimento prestado por leigos.

Esse trabalho revelou que $11,88 \%$ dos websites trazem testemunhos de pacientes, já o estudo de Miranda GE, et al. (2013) apresentou 6,51\%, mostrando que houve um aumento desse artifício utilizado pelos profissionais. Os Cirurgiões-dentistas utilizam o depoimento de pacientes como estratégia de marketing, onde, de maneira geral, os pacientes demostram sua satisfação depois de tratamentos odontológicos realizados na clínica provavelmente omitindo-se ou editando-se os depoimentos de descontentamento.

Dos websites analisados $36,88 \%$ trazem dicas de saúde bucal, 15,16\% trazem uma seção de perguntas e respostas frequentes e apenas um website na região Sul e outro na região Sudeste $(0,81 \%$ no total) trazem a data da última atualização da página. Para Miranda GE, et al. (2013) as dicas de saúde bucal são importantes para dar suporte e esclarecer eventuais dúvidas aos pacientes, referentes à importância da saúde bucal e tratamentos, tornando o atendimento mais rápido, assim como uma seção de perguntas e respostas frequentes, todavia, os websites deveriam trazer a data da última atualização, mesmo não sendo considerada uma infração ética, o fato de não atualizar as informações, pode gerar insegurança por parte do paciente que não sabe se as informações são atuais ou não.

Dos 244 websites analisados, 26,22\% trazem um sistema eletrônico para marcação de consulta, muito diferente do trabalho de Miranda GE, et al. (2013) que mostrou um percentual de apenas $5,21 \%$. O sistema eletrônico de marcação de consulta proporciona comodidade e facilidade de acesso para o paciente e representa praticidade no processo de marcação de consulta e evidencia a evolução tecnológica que vem impactando também na Odontologia. Na região Norte, $60 \%$ dos websites trazem esse dispositivo, índice considerado elevado quando comparado com a região Sudeste que apresentou $20,83 \%$.

Segundo o artigo 44, inciso XIV do CEO, constitui infração ética:

"realizar a divulgação e oferecer serviços odontológicos com finalidade mercantil e de aliciamento de pacientes, através de [...] mala direta via internet, [...] entre outros meios que caracterizem concorrência desleal e desvalorização da profissão" (CFO, 2012, p. 15).

O CEO deixa claro que só é considerada infração ética se o envio de mala direta tiver finalidade mercantil ou de aliciamento de pacientes, nesse caso, o profissional pode utilizar esse dispositivo para enviar, por exemplo, artigos com inovações odontológicas, desde que, não tenham tais finalidades (CFO, 2012).

Apenas 6,96\% dos websites possuíam cadastro de e-mail para recebimento de mala-direta eletrônica ou newsletter, contrastando com o trabalho de Serra MC, et al. (2005) que apresentou um índice bem mais elevado (26,46\%). Essa diminuição pode ter ocorrido talvez, pelo fato de o envio de mala direta ter deixado de ser uma ferramenta de marketing e ter se tornado um possível transtorno ao paciente que fica recebendo e-mails indesejados com frequência. Acrescentando-se ainda que, as regiões Norte e Centro-Oeste não apresentaram nenhum website com esse tipo de cadastro, diferentemente da região Sul que apresentou $10,71 \%$ de websites com esse item.

Poucos websites trazem um link para o CRO ou CFO (6,14\%). No trabalho de Miranda GE, et al. (2013) esse percentual foi de $9,38 \%$. Apesar de também ser um item permitido, notou-se que poucos profissionais se preocupam em fornecer aos pacientes atalhos para que eles possam ter acesso aos conselhos regional e federal. Uma vez disponibilizados esses links no website, o potencial paciente sente mais confiança, de modo 
que este, acredite que o consultório está dentro das normas, passando mais credibilidade ao profissional. As regiões Norte e Centro-oeste, não apresentaram nenhum website que fornecia algum desses links, enquanto na região Nordeste, $13,33 \%$ dos websites disponibilizam algum link de acesso ao CRO ou CFO.

\section{CONCLUSÃO}

Diversas infrações éticas são cometidas pelos cirurgiões-dentistas, a mudança dessa realidade depende da sensibilização dos profissionais para que não haja a mercantilização, concorrência desleal e consequentemente a desvalorização da categoria, bem como uma fiscalização intensiva pelos respectivos Conselhos Regionais de Odontologia, na publicidade e propaganda realizada por esses profissionais.

\section{REFERÊNCIAS}

1 BRASIL. CFO. Conselho Federal de Odontologia. CFO-118/12, de 11 de maio de 2012. Torna obrigatório constar na publicidade o nome e o número de inscrição da pessoa física ou jurídica, bem como o nome representativo da profissão de cirurgião-dentista e também das demais profissões auxiliares regulamentadas.

2 BRASIL. CFO. Conselho Federal de Odontologia. Código de Ética Odontológica aprovado pela resolução no 118/2012, de 11 de maio de 2012.

3 BRASIL. CFO. Conselho Federal de Odontologia. Dados estatísticos relativos aos profissionais, entidades e especialidades odontológicas.

4 BRASIL. CFO. Conselho Federal de Odontologia. Resolução CFO no 112 de 02 de setembro de 2011 - CFO proíbe o uso do ácido hialurônico em procedimentos odontológicos e proíbe o uso da toxina botulínica para fins estéticos na Odontologia.

5 BRASIL. CFO. Conselho Federal de Odontologia. Resolução CFO no 145 de 27 de março de 2013 - CFO Altera redação de artigos da Resolução CFO-112/2011. Resolve: Permitir o uso do ácido hialurônico em procedimentos odontológicos e permite o uso da toxina botulínica para uso terapêutico em procedimentos odontológicos e vedado para utilização em procedimentos estéticos.

6 BRASIL. CFO. Conselho Federal de Odontologia. Resolução CFO no 146 de 16 de abril de 2014 - CFO Altera o artigo $2^{\circ}$ da Resolução CFO-112/2011. Resolve: O uso da toxina botulínica será permitido para procedimentos odontológicos e vedado para fins não odontológicos.

7 BRASIL. CFO. Conselho Federal de Odontologia. Resolução CFO no 176 de 06 de setembro de 2016 - CFO Revoga as Resoluções CFO-112/2011, 145/2014 e 146/2014.

8 BRASIL. CONAR. Conselho Nacional de Auto-Regulamentação Publicitária de 22 de maio de 1980. Estabelece Impedimento da publicidade enganosa ou abusiva que cause constrangimento ao consumidor ou a empresas, defendendo a liberdade de expressão comercial.

9 BRASIL. Lei n5.081, de 24 de agosto de 1966. Regula o exercício da Odontologia.

10 BRASIL. Lei no. 8078, de 11 de setembro de 1990. Código de Defesa do Consumidor. Diário Oficial da União 12 set $1990 ; 128$ (176 supl):1.

11 GARBIN AJI, et al. Publicidade em odontologia: avaliação dos aspectos éticos envolvidos. Revista Gaúcha de Odontologia, 2010; 58(1): 85-89.

12 GONÇALEZ, MC. Publicidade e Propaganda. IESDE Brasil. 2009.

13 LIMA AIC, et al. Análise dos perfis de clínicas odontológicas e de cirurgiões-dentistas em duas redes sociais quanto aos aspectos éticos, de propaganda e publicidade. Rev Bras Odontol Leg RBOL. 2016; 3(2): 66-73.

14 MARTINS ALG, et al. Avaliação dos aspectos éticos da publicidade e propaganda odontológica divulgadas por profissionais em São Luís - MA. Revista de Pesquisa em Saúde. 2011; 12(2): 23-26.

15 MELO AUC, et al. Publicidade odontológica na internet: considerações éticas e legais. Revista da Faculdade de Odontologia. 2012; 17(2): 240-243.

16 MIRANDA GE, et al. Análise de websites de cirurgiões-dentistas quanto aos aspectos éticos e legais relativos à publicidade e propaganda. Revista Brasileira de Odontologia. 2013; 70(1): 80-84.

17 MIRANDA SS, et al. Publicidade e Propaganda em Odontologia: avaliação dos aspectos éticos envolvidos. Rev Bras Odontol Leg RBOL. 2015; 2(1): 53-67.

18 MORITA MC, et al. Perfil atual e tendências do cirurgião-dentista brasileiro. 21a . Ed. Maringá: Dental Press International; 2010.

19 NIC.BR - NÚCLEO DE INFORMAÇÃO E COORDENAÇÃO DO PONTO BR. TIC domicílios 2015: pesquisa sobre o uso das tecnologias de informação e comunicação nos domicílios brasileiros. 11. ed. São Paulo: Comitê Gestor da Internet no Brasil, 2016. 422 p.

20 PARANHOS LR, et al. Implicações éticas e legais do marketing na Odontologia. Revista Sul-Brasileira de Odontologia. 2010; 2(1): 219-24.

21 SASSI C, et al. Placas odontológicas: aspectos legais e orientações práticas. Faculdade de Odontologia de Lins/Unimep. 2013; 23(2): 25-34.

22 SERRA MC, et al. Ferramentas de marketing empregadas por cirurgiões dentistas. Revista Gaúcha de Odontologia. 2005; 53(2): 85-164. 